Robertson CMT. Alberta's infant mortality rate: the effect of the registration of live newborns weighing less than 500 grams. Can 7 Public Health 1998;89:188-9.

4. Canadian perinatal bealth report 2000. Ottawa: Health Canada; 2000.

5. Kramer MS, Platt RW, Yang H, Haglund B, Cnattingius S, Bergsjo P. Registration artifacts in international comparisons of infant mortality. Paediatr Perinat Epidemiol 2002;16:16-22.

6. Canadian perinatal bealth report 2003. Ottawa: Health Canada; 2003.

7. Births 2002. Ottawa: Statistics Canada; 2004. Cat no. 84F0210XIE. Available: www.statcan.ca/english /freepub/84F0210XIE/2002000/index.htm (accessed 2004 Nov 29).

8. Deaths 2002. Ottawa: Statistics Canada; 2004. Cat no. 84F0211XIE. Available: www.statcan.ca /english/freepub/84F0211XIE/2002000/index.htm (accessed 2004 Nov 29).

9. Woodward GL, Bienefeld MK, Ardal S. Underreporting of live births in Ontario: 1991-1997. Can 7 Public Health 2003;94:463-7.

DOI:10.1503/cmaj.1041753

\section{Outcome reporting bias in government-funded RCTs}

A n-Wen Chan and associates, ${ }^{1}$ in their evaluation of outcome reporting bias in 48 randomized controlled trials funded by the Canadian Institutes of Health Research (CIHR), found that a high number (median 26) of outcomes were declared in each protocol, but not all of these outcomes were reported in the published papers; in addition, statistically significant efficacy outcomes had a higher likelihood of being reported than nonsignificant ones.

Twenty of the 48 studies were jointly funded by industry and CIHR. It would be of interest to know whether the results were consistent between the 2 subgroups of studies, those funded by government only and those cofunded by industry.

This work shows that research promoted through public funding is not free from bias. The explanation of outcome reporting bias is challenging. In particular, further investigation is needed to identify the factors that affect selection of outcomes between a study's protocol and the published report of the study.

\section{Pasquale L. Moja}

Ivan Moschetti

Roberto D'Amico

Italian Cochrane Centre

Milan, Italy
Reference

1. Chan AW, Krle ̌̌a-Jerić K, Schmid I, Altman DG. Outcome reporting bias in randomized trials funded by the Canadian Institutes of Health Research. CMA7 2004;171(7):735-40.

Competing interests: None declared.

DOI:10.1503/cmaj.1041669

\section{[The authors respond:]}

Tn response to Pasquale Moja and as1 sociates, we would first like to clarify 2 points in their letter. First, it would be more accurate to state that a median of 26 outcomes was declared in both the protocols and the publications, rather than in the protocols alone. Also, with regard to the assertion that "research promoted through public funding is not free from bias," we would clarify that it is not the research itself that is biased, but rather the reporting of the research. ${ }^{1}$

Moja and associates ask about the consistency of results across sources of funding. We would not expect significantly greater deficiencies among trials that were jointly funded by government and industry sources, as these studies were investigator-driven rather than fully controlled by the industry sponsor. Furthermore, formal subgroup analyses would be underpowered to detect any differences.

However, we do agree that stratifying the data by funding source would provide valuable preliminary insight into factors that might affect selective outcome reporting. Exploratory post hoc analyses for efficacy outcomes revealed consistent results across funding subgroups. The odds ratios for outcome reporting bias were 3.4 (95\% confidence interval [CI] 1.3-9.3) for trials funded jointly by industry and CIHR
( $n=11$ trials) and 2.3 (95\% CI 1.1-5.1) for trials funded by CIHR alone $(n=19$ trials). The prevalence of major discrepancies in the specification of primary outcomes also did not differ significantly between jointly funded $(7 / 20,35 \%)$ or CIHR-funded (12/28, $43 \%$ ) trials.

\section{An-Wen Chan \\ Karmela Krle ̌̌a-Jerić \\ Isabelle Schmid}

Randomized Controlled Trials Unit

Canadian Institutes of Health Research

Ottawa, Ont.

Douglas G. Altman

Centre for Statistics in Medicine

Oxford, UK

\section{Reference}

1. Chan AW, Krle Sa-Jerić K, Schmid I, Altman DG. Outcome reporting bias in randomized trials funded by the Canadian Institutes of Health Research. CMA7 2004;171(7):735-40.

Competing interests: None declared.

DOI:10.1503/cmaj.1041723

\section{Medical education and chronic disease}

Aton Miller and associates, ${ }^{1}$ in A their commentary on the need to improve health care services for children with chronic health conditions, reveal one of the weaknesses of the medical profession. We have difficulty adapting to new situations, such as that presented by the increasing prevalence of chronic disease in our society.

Although we can improve patients' quality of life or soothe the burden of certain diseases, many chronic conditions simply cannot be cured, and patients will have to accept that limita- 
tion. At the same time, doctors must learn how to deal with patients who are more empowered. An interdisciplinary approach might help, but the medical curriculum will also need to be revised. The emergency department is not the best place to develop an understanding of chronic medical problems, and patient follow-up and concerned dedication must be taught. Unfortunately, faculty members are ill prepared to serve as adequate role models in this area, and strong efforts will be needed to ensure that the next generation of physicians will find the interest and motivation to provide better services to patients with chronic diseases.

\section{Serge Dubé}

Vice Dean, Professorial Affairs

Faculty of Medicine

Université de Montréal

Montréal, Que.

\section{Reference}

1. Miller AR, Recsky MA, Armstrong RW. Responding to the needs of children with chronic health conditions in an era of health services reform [editorial]. CMAF 2004;171(11):1366-7.

DOI:10.1503/cmaj.1041745

\section{[The authors respond:]}

S erge Dubé's comments illustrate an $S$ extremely important dimension of the problem of transforming health care services for people with chronic diseases. In our commentary ${ }^{1}$ we focused on the need for shifts in policy in this area, but we agree that fundamental changes in physician skills, and perhaps attitudes, will also be required for physicians to play an effective role in the continuing care of patients with chronic conditions. Considerable reform of medical education curricula and goals will be required to meet the contemporary challenge of chronic diseases. Dubé alludes to some current deficiencies. In a recent overview of this topic, Holman ${ }^{2}$ helpfully articulated details of the important role of medical education in this era of chronic disease and suggested specific learning experiences for trainees that should be offered within ambulatory care programs structured around a chronic disease model of care. These ideas could be refined and implemented within Canadian medical residency education to teach students about the types of patients they will frequently encounter over the course of their careers. Furthermore, the topic of caring for patients with chronic disorders could be introduced into longitudinal courses at the undergraduate level, to give students early exposure to the prevalence, importance and unique aspects of this domain of health care.

\section{Anton R. Miller \\ Magdalena A. Recsky \\ Robert W. Armstrong \\ Centre for Community Child Health \\ Research \\ British Columbia Research Institute for \\ Children's and Women's Health \\ Vancouver, BC \\ References \\ 1. Miller AR, Recsky MA, Armstrong RW. Re- sponding to the needs of children with chronic health conditions in an era of health services re- form [editorial]. CMA7 2004;171(11):1366-7. \\ 2. Holman H. Chronic disease - the need for a new clinical education. FAMA 2004;292(9):1057-9. \\ DOI:10.1503/cmaj.1050053}

\section{Violence in advertising}

Tam writing to express concern about the full-page advertisement for telithromycin that appeared on page 1016 of the Oct. 26 issue of CMA7 (volume 171, issue 9). The advertisement shows a man with a pistol aiming at 3 head-and-torso representations of a human body. The main function of a pistol is to injure or kill people. It is not defensible for a pharmaceutical company to use the image of a gunman to promote a drug to doctors.

Would it be possible for CMAf to refuse to run ads showing weapons such as firearms?

\section{Robert W. Shepherd \\ Family physician \\ Victoria, BC}

DOI:10.1503/cmaj.1041702

\section{[The advertiser responds:]}

W e agree with Robert Shepherd that there is no place for violence in pharmaceutical advertising. His concern over the image of a pistol in our ad gives us a welcome opportunity to discuss an issue to which we, as pharmaceutical marketers, paid a great deal of attention in developing the Ketek (telithromycin) advertising campaign.

The concept for the ad underwent several rounds of focus group testing (involving more than 300 Canadian physicians) to ensure that the brand messaging was both clear and professionally acceptable. The focus group results indicated that physicians fully understood the function of the pistol within the ad's creative framework and recognized it as a symbolic representation of the physician's armamentarium. Moreover, the physicians immediately recognized the targets as pathogens and not as representations - virtual or imagined - of real people.

In developing the advertising concept, we took the extra step of ensuring that no respiratory organs were displayed on the targets and that the images would not represent, in any way, anything that could relate to a living body.

As a final clearance, the ad was approved by the Pharmaceutical Advertising Advisory Board, an independent review agency whose primary role is to ensure that advertising of prescription drugs is accurate, balanced and evidence-based.

Our company's mission is to heal and improve quality of life. We trust that by shedding light on how we developed this ad, we have given $C M A 7$ readers a clearer picture of our intent and the significant effort that we put into all our campaigns to make them both informative and creative.

John Huss

Head, Internal Medicine Business Unit Sanofi-Aventis

DOI:10.1503/cmaj.1050029 